\title{
NETWORK ANALYSIS BY THE CODESNET APPROACH
}

\author{
Dario Antonelli, Agostino Villa \\ Politecnico di Torino - Corso Duca degli Abruzzi, 24 - 10129 - Torino, ITALY \\ dario.antonelli@polito.it, agostino.villa@polito.it
}

\begin{abstract}
The paper approaches the problem of analyzing complex industrial bodies like the clusters of enterprises in order to evaluate their performances. The analysis is based on a formal model of a cluster of SMEs, represented in terms of its structure, its organization and its interactions with the outside. The paper aims at giving a comprehensive presentation of the evaluation approach to network organization developed in the EU-funded Coordination Action CODESNET (COllaborative DEmand \& Supply NETwork), as well as of the "analysis road map" developed on the SME network model itself. A case study derived by an Italian industrial district is used to validate the proposed analysis approach.
\end{abstract}

\section{INTRODUCTION}

Analysis and evaluation of the different Industry Networks is becoming valued in European countries for pursuing effective industrial politics aiming to develop Small-Mid Enterprises (SMEs) (European Commission, 2002 and 2003). Analysis of a complex industrial structure as a cluster of collaborative enterprises has to be established on a formal unambiguous model (Albino \& Kuhtz, 2004; Samarra, 2003). The setup and application of such a model is the basis of CODESNET project. CO-DESNET is the acronym of a Coordination Action (CA) project, supported by the European Commission, started in 2004 under the coordination of Politecnico di Torino. The aim of this project and of other European projects like ECOLEAD, is to create a favorable environment for the development of SME networks. CODESNET is focused on the collaboration between industry and academia as a prerequisite for a successful evolution of the network organization in a stable paradigm. ECOLEAD aims at giving theoretical foundation for collaborative networks and at exploiting the potential of ICT infrastructures to make the collaboration feasible.

The model developed by CODESNET describes a cluster of SMEs in terms of structure, organization and interactions with the external socio-economic context (Villa \& Cassarino, 2004; Villa, 2006). This viewpoint aims at representing how efficiently the multi-SME industrial body can operate, how effectively it can be managed and how conveniently it could interact with the external markets of goods, supplies and labor.

Antonclli, D., Villa, A., 2007, in IFIP International Federation for Information Processing, Volume 243, Establishing the Foundation of Collaborative Networks; eds. Camarinha-Matos, L., Afsarmanesh, H., Novais, P., Analide, C.; (Boston: Springer), pp. 67-74. 
The final goal is to have a tool which could help in evaluating some performance indicators of a collaborative SME cluster (Gajda, 2004; Evans \& Wolf, 2005), such as to recognize a "best practice" in terms of good performance either in operating (efficient and high quality production \& servicing), or in managing the network (balanced distribution of responsibilities and good organization), or in negotiating with markets (e.g., good market penetration).

In practice, the aim of the CODESNET project is to help industrial managers and administrators along three main lines (Villa, 2006):

I. to understand the current state of a cluster or network of SMEs (e.g., how the SMEs are connected together; which type of organization is managing the network; how large is the presence of a SME network in its final market);

II. to recognize problems affecting the cluster/network life or development (e.g., how much conflicting the network organization could be; how the present organization of a SME network can be modified in order to enforce its robustness);

III. to estimate the SME cluster/network potentials in the future (e.g., how much profitable to join a network may be for a SME operating in a similar industrial sector and in the same region; how relevant are the technological innovations planned in a network).

The idea surrounding the CODESNET analysis approach rests upon the following considerations. Any SME network can be analyzed according to three complementary viewpoints:

1. analyze the production and logistic network which are connecting the collaborative SMEs, i.e.

- $\quad$ analyze the distribution of production operations among SMEs; the type of logistic organization; the production capacities of SMEs;

- estimate how the network organization can enhance the production volumes of the different SMEs, the amount of personnel employed at the different SMEs, the transport capacities over the internal logistic network.

2. analyze the governance organization, i.e.

- $\quad$ analyze the management responsibility assigned to each SME and the amount of information that each SME can use for management purpose (i.e. how the decisional power is assigned), the types of internal agreements and control mechanisms, and the types of agreements with external bodies;

- $\quad$ estimate the characters of the organization chart at the network level, the functionality of the coordination body, if any, and the coordination strategies.

3. analyze the network interactions with outside, i.e.

- analyze the types of commercial agreements with clients/suppliers, the types of strategies to manage, at the network level, both production resources and labor, the types of politics to plan, at the network level, innovation programs;

- $\quad$ estimate the dynamic evolutions of the market penetration, the labor employment, the risk-capital acquisition. 
These three viewpoints respectively correspond to three specific basic functions which the SME network usually performs, namely: (1) produce; (2) manage; (3) negotiate with suppliers, customers, potential financiers and potential employees.

In analyzing a SME network, the above listed analysis objectives can be obtained if a sufficient set of information can be collected. Two types of facts are necessary:

descriptions of existing SME networks, among which to identify the most effective and robust networks, to be considered "best practice" units;

1. scientific reports and papers presenting models of networks and discussing issues of network design, management and validation (by which industrial managers and designers could derive both personal suggestions as well as information about RTD groups to be contacted for consultancy and joint projects).

The two sets of data, namely a catalogue of scientific papers (named in the following Virtual Library) and an archive of SME networks descriptions (named Virtual Laboratory), are the keystones on which the analysis method, developed in the CODESNET project, is based.

Section 2 will deal with the "Analysis Road Map" by which an end-user can consult the CODESNET web site, by surfing from a SME network representation to related scientific papers.

Section 3 will outline how the papers' archive and the SME networks catalogue, both in a standardized format, have been arranged into the dedicated web portal (www.codesnet.polito.it) in order to be easily consulted by expert end-users.

Last section will give a survey of the set of SME networks catalogued, by showing which main features and main management/organization aspects could be found through a navigation in the CODESNET web site.

\section{THE ANALYSIS ROAD MAP}

CODESNET web portal has been arranged as an "Analysis Support System - ASS" for expert users (also called Innovation Support System - ISS, for its potential use as support of managers and designers to approach innovation programs for SME networks.

Two crucial points have been approached in designing the Analysis Support System:

1. the complexity in organizing and assuring maintenance of the SME descriptions' archive and the scientific papers' catalogue;

2. the necessity of assuring an easy exploitation of the Analysis Support System by some industrial end-user.

Typically, the utilization of an archive and catalogue concerning SME networks is expected by an industrial manager and/or technicians who should approach some innovation problem in his own industrial body. Then, searching in the archive and catalogue, he aims to rapidly fetch either a description of another SME network in which his own problem has been solved through some new approach, or a description of a solving procedure. The Analysis Support System has then been organized in such a way to help this way of searching.

The three complementary viewpoints, corresponding to the three components of any network, namely the Operation Structure, the Organisation Arrangement and the 
Interactions with Socio-Economic Context, have been adopted as the three "Main CODESNET Issues" concerning network design, management or evaluation, and have been used as key-drivers in the search within the SME networks' archive and the papers' catalogue. Each main issue plays the role of "analysis viewpoint/ approach" for an industrial user.

In a nutshell, the idea characterizing the Analysis Support System organization approach is that, once an industrial user has selected the customized "analysis viewpoint", he can then search for the registered SME networks, stored as "best practices" for the issue and the viewpoint selected, or he can search for the registered model/procedure (i.e., technical paper) facing that issue.

A scheme of the Analysis Support System driving the industrial user is sketched in Figure 1, showing the list of the "Main CODESNET Issues" for analysis purpose, organized according to the above mentioned three components of a network.

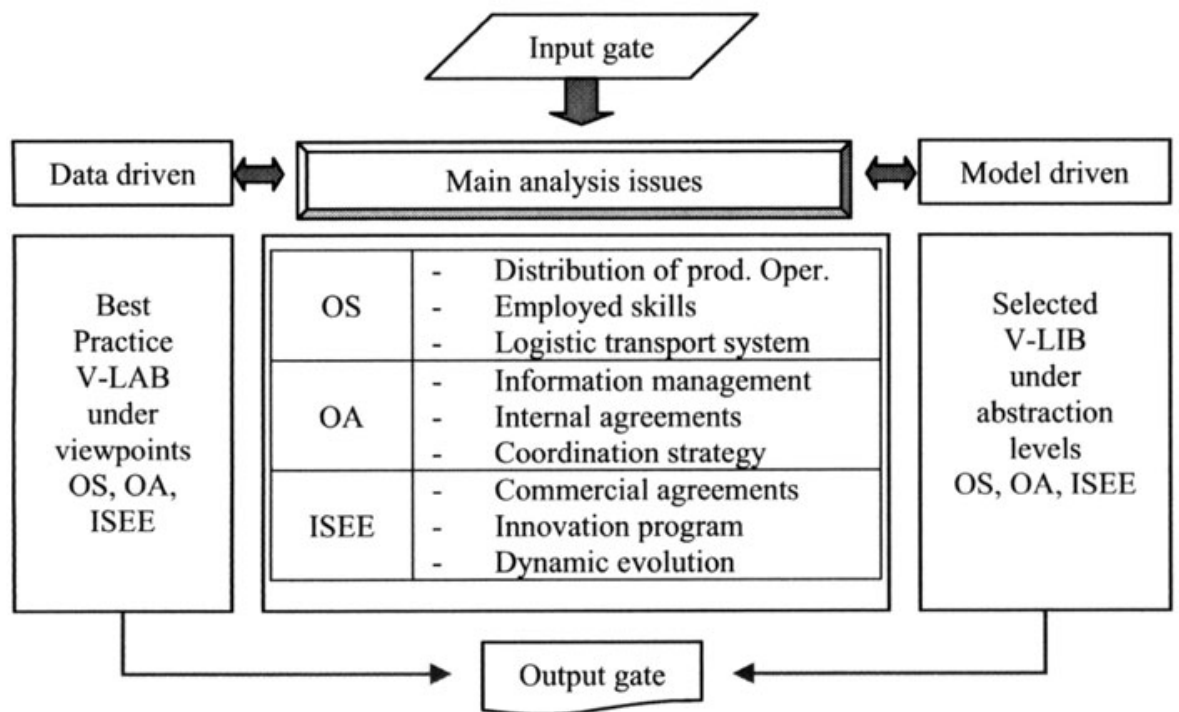

Figure 1 - A scheme of the ISS driving the professional user

From these considerations one can see the double interest of industrial end-users in the CODESNET analysis methodology here proposed:

- for each type of standard problem, to have the possibility of analyzing data sets which describe benchmark SME networks in which the values of the Performance Indicators are optimal: these SME networks are denoted innovative networks, referred to as "best practice";

- for each type of standard problem, to have the opportunity of analyzing dedicated solution procedures and technologies which specifically approach the main issue under examination.

Then, the selected list of "Main Issues" becomes the hinge of the interaction between data archive and model catalogue, for an analysis procedure to be applied according to the following steps. 


\section{Analysis Procedure Steps:}

1. An end-user enters the ASS through the list of "Main Issues" (described through a brief and easy presentation);

2. the end-user selects the "Main Issue" of his own interest;

3. starting from the selected "Main Issue", the end-user will be addressed, depending on his choice,

a. towards the data set which describes the benchmark SME network for the considered "Main Issue";

b. towards the list of models which approach that "Main Issue", together with the problem solution procedures and tools;

4. in case the direction (3-b) is selected, the end-user is finally addressed to the scientific papers related to the "Main Issue" at the beginning.

Figure 2 - Analysis Procedure

\section{OUTLINE OF THE VIRTUAL LIBRARY AND VIRTUAL LABORATORY}

The organization of scientific papers into the Virtual Library catalogue (stored in a standard format denoted V-LIB in the CODESNET web site) and of SME networks' presentations in the Virtual Laboratory archive (V-LAB) has been based on the same concept above stated, meaning the "Main CODESNET Issues".

In practice, the most qualifying attributes of a SME network can be recognized through the V-LAB format, where the nine main questions (named Main CODESNET Issues, points I to III of the Introduction) can be answered.

Depending on which main qualifying attributes of the analyzed SME network are recognized in the V-LAB format, either proper models (for network simulation, design or performance evaluation) or methods (for network management) or procedures (for network innovation and skill improvement) can be found in the archive of scientific papers, stored in the Virtual Library.

Table 1 shows the potential links suggested to the CODESNET web portal enduser. Starting from the consultation of a V-LAB format, and having interest in a particular component of the SME network (either the "Operational Structure" or the "Organisational Arrangement" or the "Interaction with the Socio-Economic Environment"), an end-user can find three typical questions for the SME network component he/she has chosen: these questions are listed in the left-side column of Table 1.

The three questions related to a SME network component can give suggestions to the end-user to search for further technical information and/or scientific models/ procedures concerning either the structure type of the network under examination (together with the internal logistics), or the governance methods and interaction agreements, or the innovation programs and required personnel skills (to be negotiated with external markets). These last information can be found in the papers catalogued in the Virtual Library. 
The portal design and maintenance facilities keep on increasing the numbers of $\mathrm{V}$-LABs and V-LIBs included and maintaining and improve the links between them. The future evolution of the CODESNET project will be the European Virtual Institute on Innovation in Industrial Networks, composed by an international Association of academic institutions, research centers and enterprises.

Table 1. Links suggested to the CODESNET web portal end-user.

\begin{tabular}{|c|c|c|}
\hline $\begin{array}{l}\text { Questions in the V-LAB } \\
\ldots\end{array}$ & $\begin{array}{l}\text {...correspond to main } \\
\text { attributes of a Network ... }\end{array}$ & $\begin{array}{l}\text {...and to the } \\
\text { following topics in } \\
\text { the V-LIB }\end{array}$ \\
\hline \multicolumn{3}{|c|}{ Re. to the "Operational Structure": } \\
\hline 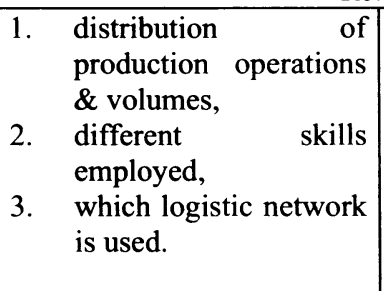 & $\begin{array}{l}\text { type: supply chain; } \\
\text { industry network; } \\
\text { scientific park; } \\
\text { development } \\
\text { agency;... } \\
\text { b) logistics (internal } \\
\text { service or outsourcing) }\end{array}$ & $\begin{array}{l}\text { I model of the product } \\
\text { processing \& transports; } \\
\text { - simulation, } \\
\text { - network design } \\
\text { - performance evaluation }\end{array}$ \\
\hline \multicolumn{3}{|c|}{ Re. to the "Organizational Arrangement": } \\
\hline $\begin{array}{ll}\text { 4. } & \begin{array}{l}\text { attribution } \\
\text { management } \\
\text { responsibilities; }\end{array} \\
\text { 5. } & \text { internal agreements, or } \\
\text { control mechanisms; } \\
6 . & \begin{array}{l}\text { organization chart or } \\
\text { coordination strategy. }\end{array}\end{array}$ & 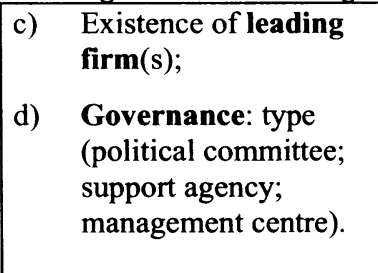 & $\begin{array}{l}\text { II organizational chart } \\
\text { of the governance } \\
\text { committee: } \\
\text { - enforce cooperation } \\
\text { - assure coordination }\end{array}$ \\
\hline \multicolumn{3}{|c|}{ Re. to the "Interaction with the Socio-Economic Environment": } \\
\hline 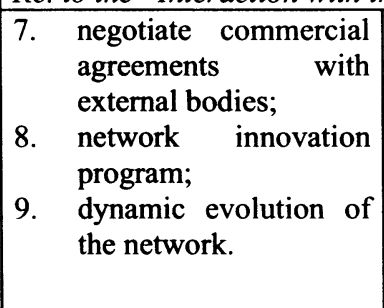 & $\begin{array}{l}\text { e) } \begin{array}{l}\text { Personnel skill level } \\
\text { and qualification; }\end{array} \\
\text { f) Innovation programs } \\
\text { through interactions } \\
\text { with universities and } \\
\text { RTD centres. }\end{array}$ & 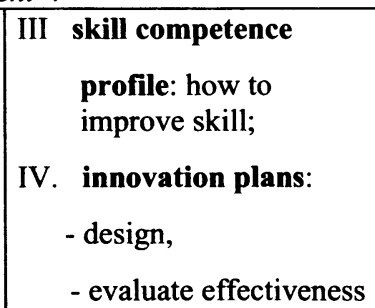 \\
\hline
\end{tabular}

\section{ANALYSIS CONSIDERATIONS FROM THE VIRTUAL LABORATORY}

A typical analysis of the SME networks and clusters catalogued in the Virtual Laboratory has been done in order to focus main features of the different industrial bodies presently stored in the web portal. To perform such an analysis, a selected set of V-LAB formats have been considered. Four characteristics were investigated:

a. the type of industrial body, i.e., either a Supply Chain, or a Network/District, or a Scientific Park, or a Development Agency; 
b. the type of governance, i.e., through either a Cluster/Network Committee, or a Leading Firm, or a Support/Coordination Agency, or through Individual Agreements;

c. the requests for personnel skills, i.e. in terms of high-level skills, or specialised skills, or many skills without any special request;

d. the presence of innovation programs.

First, the numbers of enterprises included in the different types of bodies seem to belong to specific value ranges. Scientific Parks include more frequently from 10 to 100 enterprises, depending on the dimensions of the enterprises: in case of larger enterprises, the number is lower, thus showing a specific goal or scope of the park, like promoting a balanced network of (usually) high-specialization firms. Alternatively, in case of smaller enterprises, the role of the scientific park appears to be that of promotion and support agency.

The industrial districts range from ten to hundredth firms. This pattern of firm groupings, however, does not seem to be sufficiently motivated: it could be a characteristic of the set of collected networks. Indeed, the aim of the consortium was to have clear information on some industrial districts, mainly in the Italian and French countries: this can make the sample excessively polarized.

A clear pattern occurs for Supply Chains, which ranges from hundreds to thousands of components. This is a typical organisation in several supply chains operating in a specific industrial sector producing mass customised products (as for automotive or electronic goods).

Regarding Development Agencies, a specific French organization, only a few similar data are available. However, their main features are really interesting for a comparison with the Scientific Park as they present similar mission.

A second analysis has been centered on the kind of governance (i.e., Organizational Arrangement), which has been classified either as Cluster/Network Committees, or by the presence of a Leading Firm, or by a Support/Coordination Agency. Considering this second character, the difference among the types of analyzed industrial bodies seems to be more recognizable.

Among the considered networks, the presence of a committee is usual: this feature has also been detected in a number of other similar districts. A smaller number of networks show evidence of leading firms: usually this pattern can be found in districts producing customized goods (e.g., jewels), where leaders are firms which also denote the district trade mark. Presence of individual agreements linking the component firms rarely occurs in the set of analyzed districts: however, in several industrial sectors, this percentage should be greater than the detected one.

Considering the Supply Chains, both the presence of coordination committees, and of Support Agencies and of Leading Firms can be found: no special type of governance can be recognized. However, a different situation between a supply chain managed by either a committee or a support agency, on one side, and that controlled by a leading firm, is related to the type of production and the dimensions of enterprises there included: in the former case, firms of similar dimensions agree in having a coordination structure for managing the production flows as well as the interactions with markets; in the latter, the leader drives all the chain, being usually the enterprise at the end of the chain and the final product supplier.

In case of Scientific Parks, a prevalence of Support Agencies can be seen, with respect to presence of leaders. The first situation is the usual one both in Italian 
parks, and in the French "poles of competitiveness". Finally, in the few Development Agencies here detected, only coordination committees are present.

Good suggestions come by considering the requested skills of personnel employed in the analyzed industrial bodies. A variety of skill types - i.e., high-level skills, or specialised skills, or many skills without any special request - can be found both in the Supply Chains and in the industrial districts: this sparse pattern depends on the usual Operation Structures of these two organisations, meaning lines or networks for mass production of consumer goods, calling for any type of skill, from workers to designers (a few) and to managers. On the contrary, Scientific Parks only call for high-level skills, thus justifying their function of promotion and support agency already recognised by considering both the number of enclosed firms and the usual types of governance.

Finally, other complementary good considerations can be done by summarising the numbers of different industrial bodies which have started innovation programs or not. The percentages can be seen in the following small (but interesting) table:

Table 2. Links suggested to the CODESNET web portal end-user.

\begin{tabular}{|c|c|c|c|c|}
\hline Innovation & $\begin{array}{c}\text { Supply } \\
\text { Chains }\end{array}$ & Districts/networks & $\begin{array}{c}\text { Scientific } \\
\text { Parks }\end{array}$ & $\begin{array}{c}\text { Support } \\
\text { Agencies }\end{array}$ \\
\hline Yes & $27 \%$ & $33 \%$ & $70 \%$ & N.A. \\
\hline No & $73 \%$ & $66 \%$ & $30 \%$ & N.A. \\
\hline
\end{tabular}

The last data, referred to Support Agencies, are too small to be significant.

For the other ones, the estimated percentage of industrial bodies launching innovation programs or having innovation actions under development gives a clear answer to the initial question: "is the action of supporting chains and networks a good social-political strategy for Europe?" The answer now is clear: these industrial bodies, are not yet equipped with a robust organization for an effective and stable governance and they need to be supported to guarantee their survival in the worldwide markets.

\section{REFERENCES}

1. Alberti F. The governance of industrial districts: a theoretical footing proposal. Liuc Papers n. 82, Serie Piccola e Media Impresa 5, January 2001.

2. Albino V., Kühtz S., Enterprise input-output model for local sustainable development - the case of a tiles manufacturer in Italy, Resources, Conservation and Recycling, 2004, 41, 165-176.

3. European Commission, Regional Clusters in Europe, Observatory of European SMEs 2002/ No 3, Enterprise Publication, http://europa.eu.int/comm/enterprise.

4. European Commission, SMEs and Cooperation, Observatory of European SMEs 2003/ No 5, Enterprise Publication, http://europa.eu.int/comm/enterprise.

5. Evans P., Wolf B., Collaboration Rules, Harvard Business Review, the High Performance Organization, July-August 2005.

6. Gajda R., Utilizing Collaboration Theory to Evaluate Strategic Alliances, The American Journal of Evaluation, Volume: 25, Issue: 1, Spring, 2004, pp. 65-77.

7. Samarra A., Lo sviluppo nei distretti industriali, Percorsi evolutivi fra globalizzazione e localizzazione, Carocci, 2003, Roma (in Italian).

8. Villa A., Cassarino, I, "Management of a multi-agent demand \& supply network", Proc. IFAC Conference on Advanced Control Strategies for Social and Economic Systems, Vienna, 2004.

9. Villa A., "Reinforcing industrial districts: need for a structured approach", Keynote paper, 12th IFAC Symp. on Information Control Problems in Manufact., St. Etienne, Vol.1, pp. 55-66, 2006. 